\title{
MARIXO: DESENVOLVIMENTO DE UMA COLEÇÃO DIDÁTICA E CIENTÍFICA SOBRE LIXO MARINHO E ANÁLISE DE SUA EFICIÊNCIA COMO FERRAMENTA DE EDUCAÇÃO AMBIENTAL
}

Heloisa Ribeiro da Silva ${ }^{1}$

Allan Paul Krelling ${ }^{2}$

Resumo: Observa-se uma crescente preocupação com o lixo marinho. Entretanto, a distância entre a literatura acadêmica e um público mais ampliado, como estudantes do ensino médio, destaca a necessidade de se propor outras abordagens sobre o tema. Sabendo-se que a apreciação visual, por meio de exposições, aulas práticas e em campo, torna mais interessante o aprendizado, o presente trabalho tem como objetivo avaliar a efetividade das coleções didáticas e científicas como ferramenta de sensibilização sobre a temática do lixo marinho. A montagem da coleção "Marixo", do campus Paranaguá do IFPR, se deu por meio de coletas dos resíduos encontrados nas praias do litoral do Paraná, entre os períodos de 2015 e 2016. Os resíduos foram lavados, secos e separados de acordo com sua composição, sua forma e origem mais provável para serem acondicionados em potes de vidro. Após montagem da coleção, foi realizada uma exposição e a aplicação de questionário aos visitantes. De acordo com os resultados, $100 \%$ das pessoas $(n=30)$ consideraram que a coleção pode contribuir com uma maior sensibilização da sociedade, recomendando-se que um maior número de indivíduos seja envolvido nessas ações de promoção da ciência.

Palavras-chave: Coleções Didáticas; Coleções Científicas; Lixo Marinho; Lixo no Mar; Resíduos Sólidos.

\footnotetext{
${ }^{1}$ Universidade Federal da Integração Latino-Americana - UNILA, Foz do Iguaçu - PR, E-mail: ribeiroheloisa4@gmail.com

2 Docente do curso Técnico em Meio Ambiente, Instituto Federal do Paraná, Campus Paranaguá. E-mail: allan.krelling@ifpr.edu.br
} 


\section{Introdução}

O Brasil possui aproximadamente 8.500 quilômetros de linha de costa, dos quais 100 quilômetros, aproximadamente, pertencem ao litoral do Paraná. $O$ litoral é dividido em sete municípios, sendo um deles, Pontal do Paraná, o destino para vários turistas em busca do turismo de sol e praia. As praias são um dos principais espaços destinados ao lazer, tendo um custo baixo de visitação, sendo assim, acessível a todas as camadas sociais. Por possuir essa característica, as praias tornam-se alvo de uma crescente exploração comercial, sobretudo informal (BARBOSA et al., 2012).

Seu grande potencial turístico proveniente das características ambientais locais faz com que a atividade comercial envolvendo o litoral, passe a ser um causador de poluição. Dessa forma, as características socioeconômicas positivas dessa atividade (i.e. grande número de clientes) acabam gerando problemas ambientais, como o aumento da geração do lixo marinho. Lixo marinho é uma das principais formas de poluição dos mares e que, por definição, é todo resíduo sólido ou manufaturado que entra em contato com 0 ambiente marinho, independentemente de sua fonte (marinha ou terrestre) (COE; ROGERS, 1997). O lixo marinho pode provocar danos nocivos, tais como danos aos recursos hídricos e à vida marinha (PEREIRA, 2014). Os resíduos marinhos vêm se tornando cada vez mais um risco potencial à atividade econômica em praias.

Segundo Araújo e Costa (2003), o lixo marinho é o principal causador da degradação visual e da perda estética. Já que o brasileiro frequenta muito a praia, o mesmo acaba por escolher seu destino de acordo com sua beleza cênica-visual. Dessa forma, é possível afirmar que os problemas ambientais gerados pela presença de resíduos sólidos nas praias, retroalimentam perdas socioeconômicas. Essas perdas podem representar a dissuasão de até $85 \%$ de usuários de algumas praias do litoral do Paraná. Isso representaria perdas potenciais de aproximadamente $39 \%$ da renda advinda do turismo, e os efeitos econômicos podem chegar a 8,1 milhões de dólares anuais (KRELLING et al., 2017). Dessa forma, torna-se fundamental sensibilizar as pessoas para os riscos latentes da presença de lixo marinho em praias. Entretanto, para que o conhecimento sobre os impactos do lixo marinho atinja o maior número de indivíduos, torna-se vital adotar estratégias alternativas.

Krasilchik (2008) comenta que o aprendizado é melhor e mais imediato quando os interessados se encontram presencialmente com o objeto de estudo. Com isso, materiais didáticos baseados na interação entre o agente e o objeto, por exemplo, iniciativas de ciência cidadã ou ainda exposições interativas, crescem no meio acadêmico. Da mesma forma, as coleções são instrumentos comumente utilizados em instituições de ensino e pesquisa, e podem reunir diferentes exemplares de amostras de interesse oceanográfico, geológicos, biológicos, entre outros.

A partir dessas compreensões, o objetivo geral do presente trabalho foi 
sensibilização sobre a temática do lixo marinho. Para isso, três objetivos específicos foram estabelecidos (i) demonstrar o processo de criação e montagem da coleção, (ii) demonstrar o desenvolvimento de materiais para a divulgação científica (coleção e banners) gerando exposições com esses materiais e (iii) avaliar 0 potencial da exposição como ferramenta de sensibilização dos seus visitantes.

\section{Referencial Teórico}

\section{O lixo no ambiente praial}

Na região costeira estão concentradas atividades socioeconômicas que são grandes fontes geradoras de resíduos. Segundo Whitmire et al. (2017), 80\% do lixo marinho é de origem terrestre. Muitas vezes, os resíduos coletados nessas regiões acabam sendo levados para lixões a céu aberto ou são descartados em aterros onde não recebem a devida separação. Adicionalmente, existem casos onde esses resíduos acabam sendo descartados perto de rios ou mares, ou até em áreas de preservação, resultando em impactos ambientais ainda piores (ARAÚJO; COSTA, 2003: p.65).

No entanto, grande parte desses resíduos poderia ser reciclada e acaba não sendo, pois uma parte do público desconsidera sua responsabilidade na manutenção da limpeza de espaços públicos de lazer, como as praias. Essa falta de comprometimento também resulta em impactos negativos que afetam muitas comunidades tradicionais como, por exemplo, os pescadores artesanais. As reclamações mais comuns dessas populações são a presença de resíduos de polietileno nas linhas e redes de pesca, que podem até causar lesões nos indivíduos (ARAÚJO; COSTA, 2003: p.66).

Todos esses resíduos que podem ser considerados sólidos e/ou manufaturados, independente da sua fonte, que entram em contato com o ambiente marinho, são considerados lixo marinho e, mais recentemente, são também chamados de lixo no mar. O mesmo provoca ou pode vir a provocar efeitos nocivos como danos aos recursos vivos, sendo considerada principal fonte de poluição do mar (COE; ROGERS, 1997).

O termo lixo no mar tem sido usado atualmente por algumas fontes de informações, que têm o intuito de disseminar informações sobre os problemas socioambientais do país e de mostrar formas de políticas utilizadas para combatê-las. Um exemplo é a entrevista disponível no site do Ministério do Meio Ambiente, intitulada "Sarney Filho reafirma combate ao lixo no mar", onde a autora ressalta a fala de um ministro preocupado em manter a saúde preservada das baleias do Atlântico Sul (VERDI, 2017).

O lixo marinho se distribui globalmente, e estima-se que $15 \%$ são encontrados em praias e zonas costeiras, outros $15 \%$ estão na superfície e na coluna de água, e os $70 \%$ restantes estão longe de qualquer percepção visual,

pois estão no fundo do mar (CORREIA, 2016). Estes itens podem vir a causar 
danos a toda e qualquer região costeira que se utiliza do turismo como fonte de renda e de lazer.

Anteriormente, o resíduo acumulado nas praias e nos rios, era consideravelmente desagradável, apenas, aos olhos, sendo as questões ambientais consideradas em segundo plano. Atualmente, sabe-se que além da perda visual estética, o resíduo pode trazer prejuízos biológicos tanto quanto socioeconômicos ao ambiente (ARAÚJO; COSTA, 2003).

A região costeiro-litorânea do Paraná é um dos principais pontos turísticos durante as temporadas de verão, tanto para veranistas quanto para turistas. Com isso, durante a temporada ocorre aumento populacional significativo no litoral e aumentando, consequentemente, a geração de resíduos sólidos nas cidades e nas praias. Bem como no restante das praias brasileiras, o lixo depositado nas praias do Paraná pode ter sido deixado pelos banhistas, transportado pelos rios que cruzam zonas urbanas ou trazido pelas correntes marinhas (RODRIGUES; FRIEDRICH, 2017).

\section{Exposições como ferramenta de aprendizado e sensibilização}

A apreciação visual de qualquer tipo de material ou de diferentes organismos, por meio de exposições, aulas práticas e em campo, torna mais interessante o aprendizado do que apenas ouvir falar dos mesmos em sala de aula (KRASILCHIK, 2008). Com isso, o espaço das exposições no meio didático vem crescendo, trazendo então uma nova experiência aos alunos.

Em coleções podem-se encontrar diferentes objetos, com características científicas ou com caráter didático (MARANDINO et al., 2009). Uma das diferenças entre coleções didáticas e coleções científicas é o público-alvo. No geral a coleção didática tem um enfoque em amostras grandes, possuindo cores atrativas, material de vários locais etc. A etiquetagem ou procedência do material não possui grande relevância e seu condicionamento se baseia mais pelo espaço disponível do que por uma organização sistêmica. Já as coleções científicas são criadas usando um conjunto de técnicas de coleta e de análise, onde a montagem e a preservação são pontos cruciais. $E$ comumente, as coleções científicas podem ser utilizadas como uma fonte de informação (DURRELL; DURRELL, 1996).

Os meios de comunicação, que promovem a aproximação do conhecimento científico à sociedade (BORGES, 2012), bem como os materiais de divulgação científica são indícios de contribuições importantes para o crescimento das abordagens contextualizadas para a sala de aula. Essas ferramentas mostram potencialidades quando há a contextualização e o direcionamento a diferentes tipos de abordagens, contribuindo então para a ruptura do modelo linear de ensino, onde ainda não se possui espaço para ferramentas desse contexto (BINSFELD; ZANON, 1996). Esses aspectos apontados vão, ainda, ao encontro das recomendações curriculares para 0 
ensino das ciências que sugerem que se deva ocorrer à valorização desse tipo de estratégias didáticas durante o período básico de escolarização.

As características que os materiais de divulgação científica têm, muitas vezes, faltam em alguns materiais didáticos, por exemplo. E talvez a principal característica, a vinculação do tema ou informação com a realidade local da sociedade. Dessa forma, é ainda necessário que estas abordagens tenham uma maior dedicação de estudo e trabalho, para que então possam ser aplicadas de maneira eficazes (BORGES, 2012). Com isso, destaca-se a importância do planejamento, a sistematização e o feedback, para se obter a percepção do público em relação ao que se está apresentando, especialmente para compreender se essa ferramenta está sendo aproveitada como veículo de conhecimento e informação.

Todos os métodos de montagem de materiais de divulgação científica conversam com a Educação Ambiental (EA). A Educação Ambiental foi regulamentada no ano de 1999, seguindo a aprovação da Lei no 9.795 e com o Decreto $n^{0} 4.821$ de 2002, estabelecendo a Política Nacional de Educação Ambiental, trazendo grande esperança para todos os educadores ambientais. Nesse contexto a educação formal e não formal passa a fazer parte da PNEA, de forma não operacionalizada, contudo, o que representa um dilema que a própria política não consegue resolver. Todavia, a partir dos seus princípios é possível extrair algumas diretrizes comuns, como a visão da complexidade que engloba as questões ambientais (MAEKAWA, et al., 2007). O que gera a possibilidade de existir e executar diversos trabalhos que possuam relação com a Educação Ambiental. Dessa forma, as coleções didáticas e científicas vêm mostrando seu caráter de aprendizado e sensibilização, passando a acrescentar cada vez mais a cultura da preservação e cuidado, juntamente com a sensibilização no cotidiano da população.

\section{Materiais e Métodos}

A metodologia aplicada à montagem da coleção se deu por meio de coletas do material, que se estenderam entre os períodos de 2015 e 2016, os materiais foram coletados da faixa terrestre de praia. Foram utilizados diversos pontos de amostragem, mas todos localizados nos municípios de Pontal do Paraná (Canto das Pedras, Coruja, Guapê, Praia 2) e Paranaguá (Ponta Oeste - Ilha do Mel). Como primeiro passo após coleta, os resíduos foram lavados em água corrente para retirar o excesso de areia que a amostra apresentava. Em seguida, procedeu-se a secagem dos itens, colocando-os em bacias retangulares e expostos ao sol. Para o acondicionamento definitivo da coleção, foram reutilizados potes de vidro (Figuras 1a e 1b) que anteriormente serviam para compotas e conservas. Os recipientes possuem tamanho limitado para facilitar o transporte e o armazenamento. Os potes foram doados por discentes, docentes e técnicos do IFPR-Paranaguá durante uma campanha de arrecadação (Figura 2). Para facilitar a visualização dos itens acondicionados, os recipientes foram limpos e os rótulos retirados.

Revbea, São Paulo, V. 14, № 4: 09-24, 2019.

revista brasileira educação ambiental 


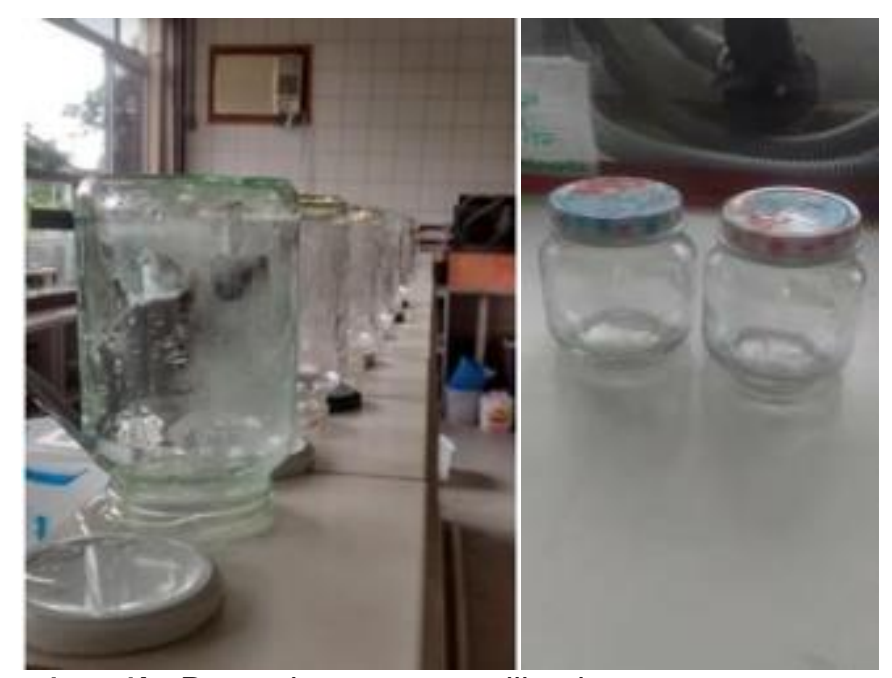

Figuras 1a e 1b: Potes de conserva utilizados para armazenamento.

Fonte: Autoria própria.

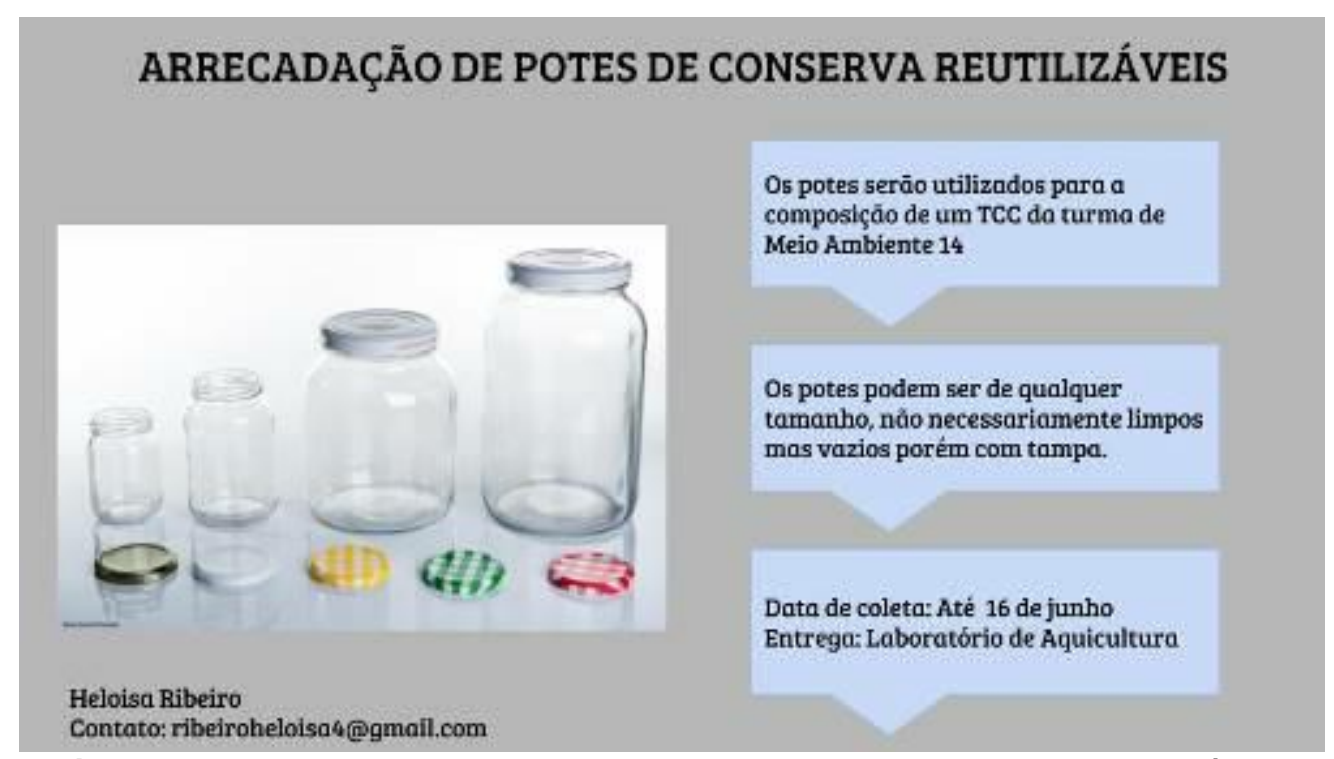

Figura 2: Folder da campanha da arrecadação de potes. Fonte: Autoria própria.

Os materiais da coleção passaram pelo primeiro processo de triagem, escolhendo-se apenas os itens que cabiam nos recipientes disponíveis. Os que não cabiam foram separados por composição e destinados para a reciclagem.

Posteriormente, os materiais já selecionados passaram pela separação entre os tipos dos materiais, por composição e forma, seguindo a metodologia de Cheshire (2009). Pela composição foram separados em plástico, isopor/espuma, tecido, vidro e cerâmica, metal, papel, borracha, madeira ou outros. Já as formas são classificadas em 80 formatos diferentes, segundo o mesmo autor, como exemplificado no Quadro 1. As formas utilizadas para o presente trabalho foram apenas aquelas que caberiam nos recipientes, incluindo-se algumas amostras menores de dois cm (Figuras $3 a$ e $3 b$ ). 
Quadro 1: Demonstração de tabela utilizada para catalogar materiais de acordo com o autor Cheshire (2009).

\begin{tabular}{|c|c|c|}
\hline COMPOSIÇÃO & FORMA (Código) & DESCRIÇÃO \\
\hline PLÁSTICO & 1 & TAMPAS E TAMPINHAS \\
\hline TECIDO & 30 & PALMILHA DE SAPATO \\
\hline BORRACHA & 66 & EVA \\
\hline
\end{tabular}

Fonte: Autoria própria.
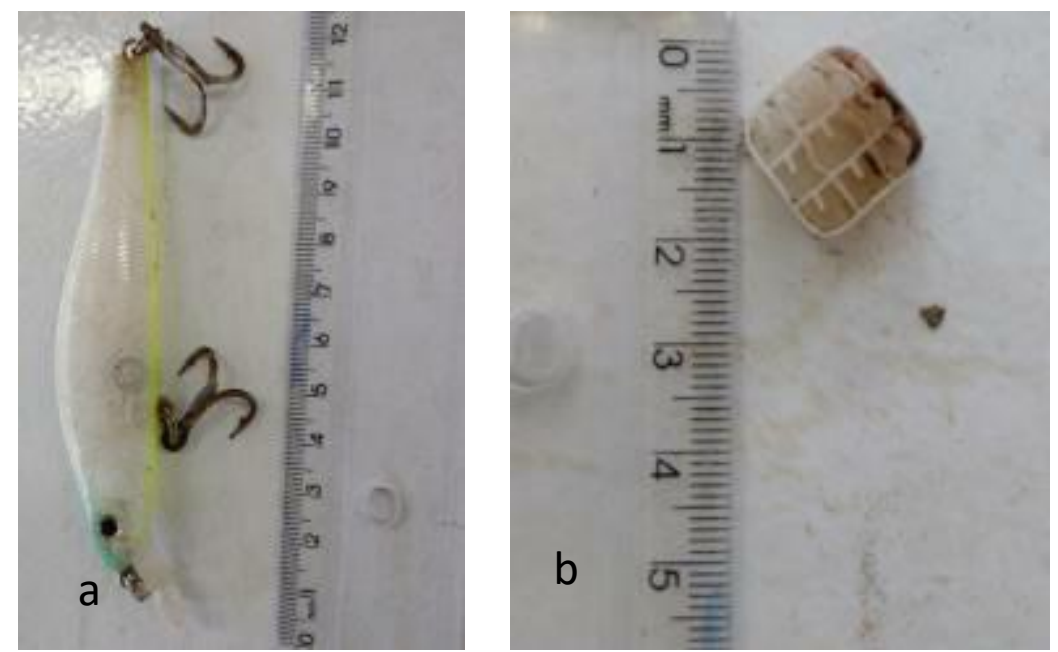

Figuras 3a e 3b: Medição de materiais; Fonte: Autoria própria.

Após essa etapa, os resíduos também foram classificados de acordo com sua origem mais provável (WILLIAMS, 2004; Figura 4), como provenientes de pesca, sanitário/esgoto, domiciliar, indeterminado, porto e usuário de praia. Todos os dados recolhidos foram tabulados. Aqueles materiais que possuíam a mesma forma, dada por Cheshire 2009, foram inseridos juntos no mesmo recipiente, para que pudessem ter uma visualização melhor. Dessa forma, em alguns casos, foram utilizados materiais de diferentes origens em um mesmo recipiente. O processo de etiquetagem foi realizado em dois dias, no primeiro as etiquetas foram confeccionadas e impressas e no segundo dia os recipientes foram etiquetados.

Outros materiais produzidos durante o processo da coleção foram os materiais ilustrativos (banners), para que pudessem ser utilizados nas formas virtual e impressa. Um dos banners foi idealizado para a utilização em um evento, o VI Seminário de Extensão, Ensino, Pesquisa e Inovação do IFPR (SEPIN), onde se apresentou um resumo do trabalho no evento e o mesmo banner poderia ser posteriormente utilizado para a exposição (Figura 5). 


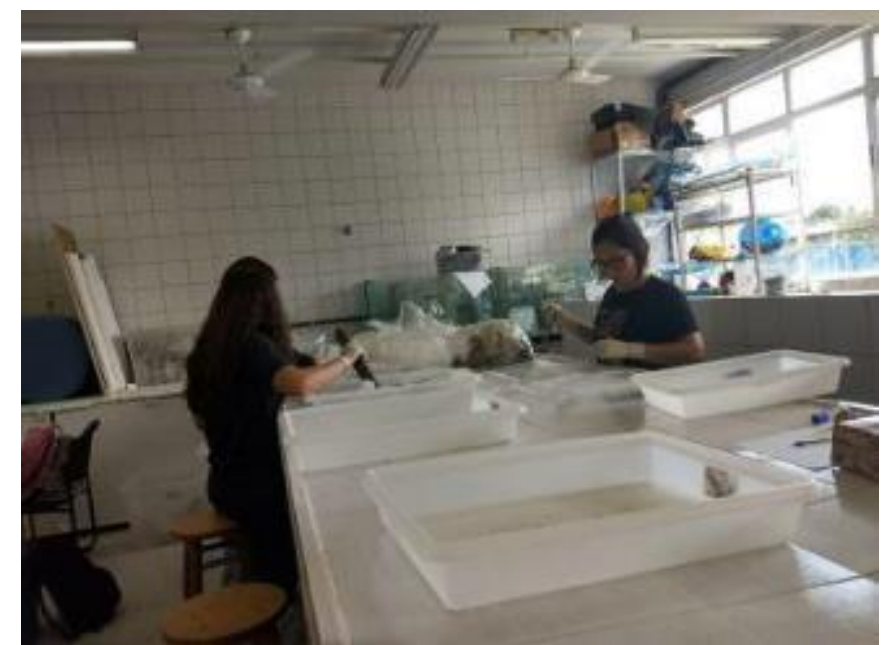

Figura 4: Triagem dos materiais pelas voluntárias do projeto. Fonte: Autoria própria.

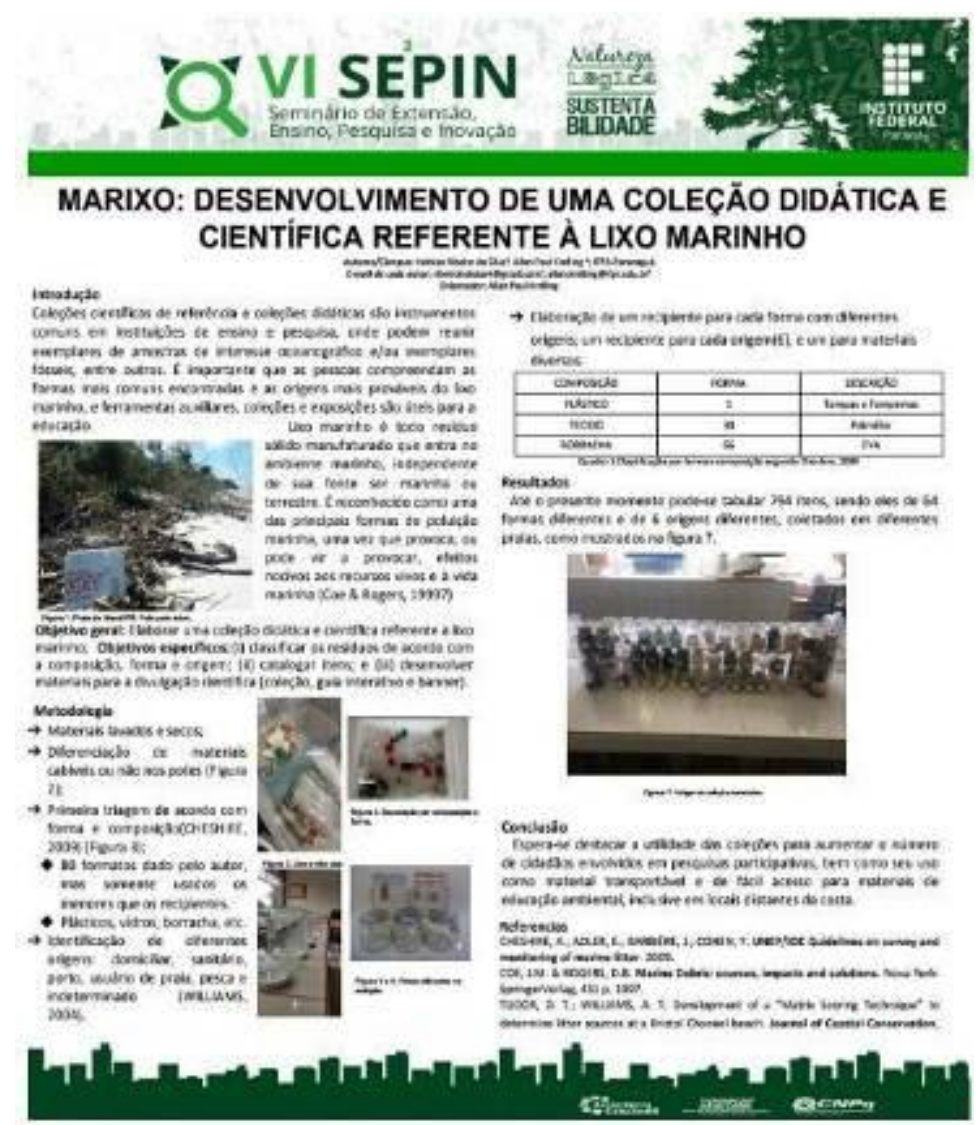

Figura 5: Banner utilizado no VI SEPIN.

A exposição foi realizada no dia 10 de novembro de 2017, a mesma foi disposta no espaço de interação do IFPR (Figura 6), em frente ao Laboratório de Conservação e Manejo, e foi divulgada por meio de um folder (Figura 7) elaborado por uma das voluntárias do Projeto. A mesma utilizou-se da metodologia de explicação e fundamentação teórica sobre o tema referente, também como a explicação sobre a montagem da coleção. Durante a exposição 
os visitantes puderam interagir com os materiais da coleção, movendo-os de lugar, sem regras rígidas para isso. Apenas, não era permitido que se abrisse os recipientes, como forma de evitar contaminação dos participantes que não usavam luvas. Para apenas um dos recipientes foi permitida a abertura, pois esse possuía exemplares de materiais incrustados, mas ainda assim seguiu-se um padrão de higiene (uso de luvas e controle do manuseio) para não causar riscos aos participantes, por serem também materiais perfuro-cortantes.

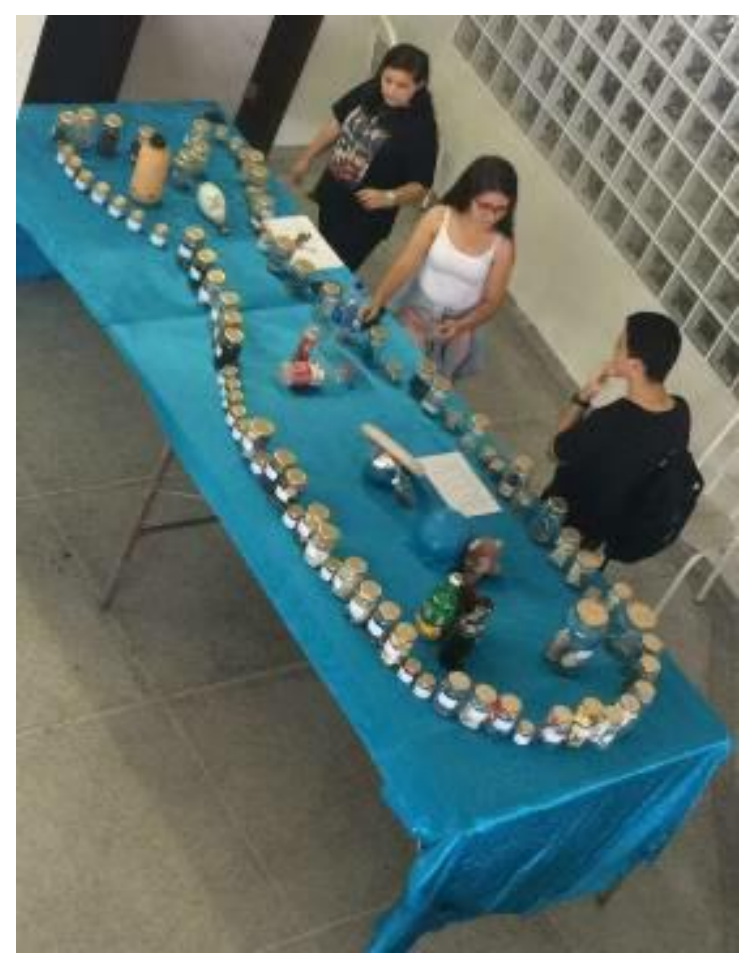

Figura 6: Exposição montada em frente ao laboratório de conservação e manejo. Fonte: Edymari Gonzaga.

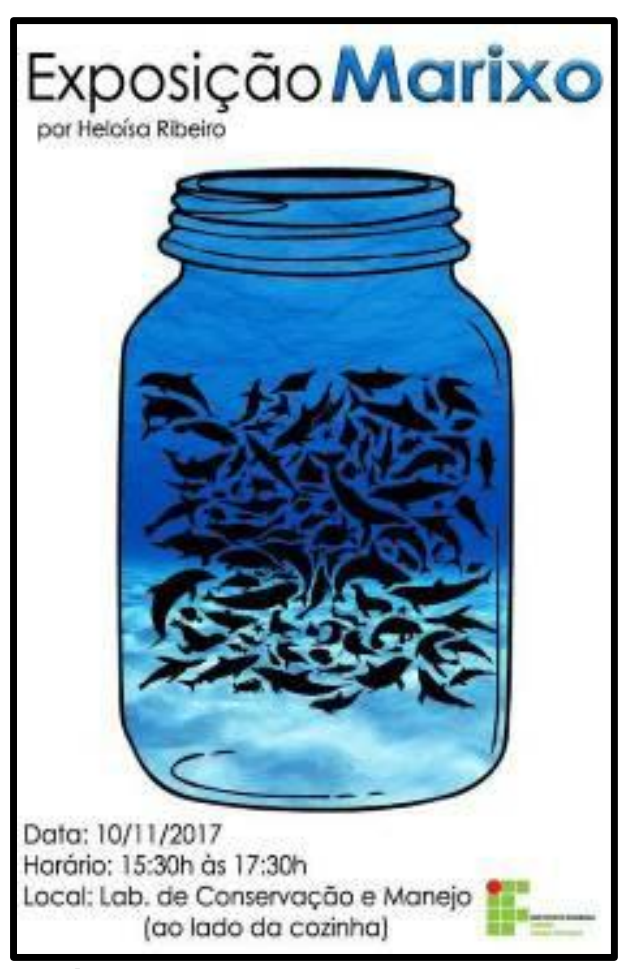

Figura 7: Folder de divulgação da exposição da coleção.

Fonte: Juliana Araújo.

Durante a exposição, foi aplicado um questionário constituído por cinco perguntas, as perguntas do 1 a 4 estavam relacionadas a avaliar: a aptidão da coleção como ferramenta de sensibilização; o tipo de abordagem adotado; se o material conseguia transmitir conhecimentos técnicos de forma satisfatória; e como o participante se sentiu após a exposição. A última pergunta convidava, ainda, o participante a contribuir com comentários, caso julga-se interessante. As perguntas tinham três opções de respostas (sim, não e não sei). Em todas as questões permitiam-se complementações escritas, através de um campo "justificativa". Na questão 4, o visitante era convidado a selecionar dentre 7 opções de estados emocionais, incluindo a opção de "outro" (onde era permitido acrescentar outros sentimentos), os estados sentimentais e emocionais que melhor representavam sua percepção sobre o tema, após a intervenção da exposição. Não era obrigado identificar-se com nome no questionário, somente definir se docente/técnico administrativo/terceirizado ou aluno (a). Caso fosse aluno, não precisaria especificar a turma apenas o curso. Foram aplicados 34 
questionários sendo eles de 30 alunos e 4 docentes/técnicos administrativos/terceirizados. Cada pergunta foi tabulada e avaliada individualmente por meio de gráficos, mas somente os questionários respondidos por alunos foram utilizados, para assim avaliar a efetividade de acordo com o número de respostas positivas e/ou negativas das perguntas. Com base nos dados obtidos, realizou-se uma análise estatística comparando as turmas de Ensino Médio Técnico em Meio Ambiente com as outras turmas (mecânica e informática), no intuito de identificar se o curso interfere na percepção. Essa análise foi feita por meio do chi-quadrado, as perguntas foram analisadas através da abundância absoluta de respostas. Para o teste de hipótese aceitava-se $h_{0}(p$-valor $\geq 0,001)$ caso o curso técnico frequentado pelo aluno não influenciasse a resposta fornecida e refutava-se $h_{0}$ ( $p$-valor $\left.<0,001\right)$ caso o curso técnico frequentado pelo aluno houvesse influenciado a resposta fornecida.

\section{Resultados e discussão}

Como primeiro resultado do trabalho se obteve a coleção, onde foi possível confeccionar 80 potes distintos (Figura 8). Neles foi possível observar 59 formatos diferentes (CHESHIRE, 2009), onde também se pode observar a presença de itens de todas as seis origens: pesca, domiciliar, sanitário/esgoto, usuário de praia, porto e indeterminado (WILLIAMS, 2004; Figura 9).

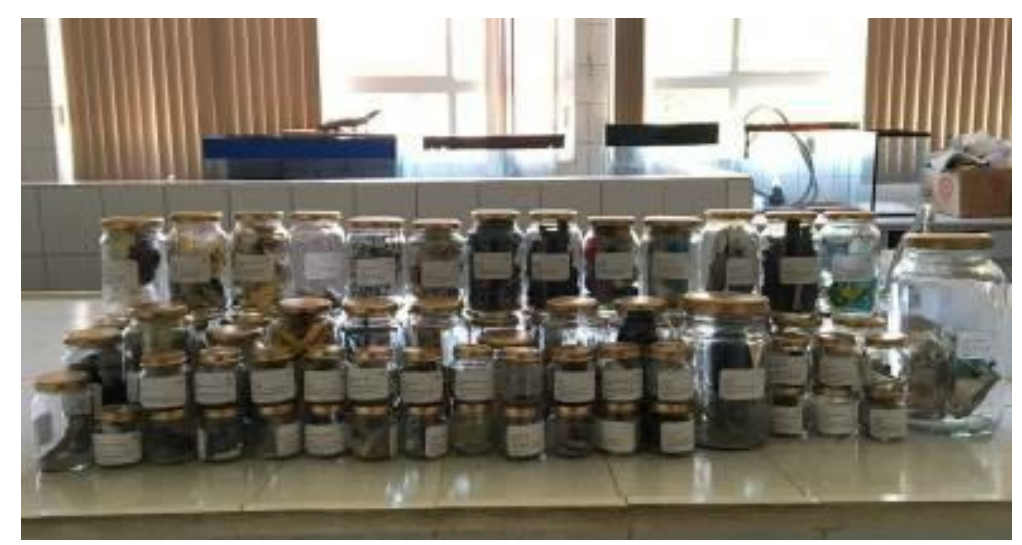

Figura 8: Todos os potes confeccionados da coleção.

Fonte: Eduarda Lopes.

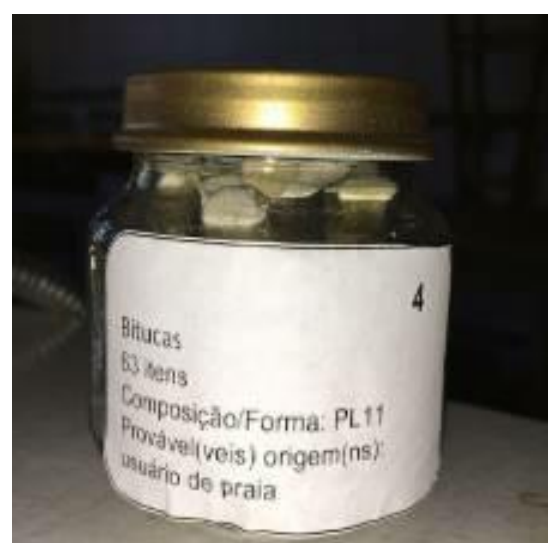

Figura 9: Exemplo de pote confeccionado, identificando o método de etiquetagem. Fonte: Eduarda Lopes.

Com a identificação dos potes pode-se também contabilizar 844 itens de 10 composições diferentes sendo eles plástico, isopor, vidro/cerâmica, tecido, papel, borracha, madeira, metal, variado e outros. Nove das composições se deram a partir do autor Cheshire (2009) e uma foi criada (variado) para fins didáticos e melhor visualização das incrustações durante a exposição. Como esperado, houve a dominância dos plásticos e mais de $60 \%$ dos potes continham a composição plástica no seu interior (Figura 10). 


\section{Composição}

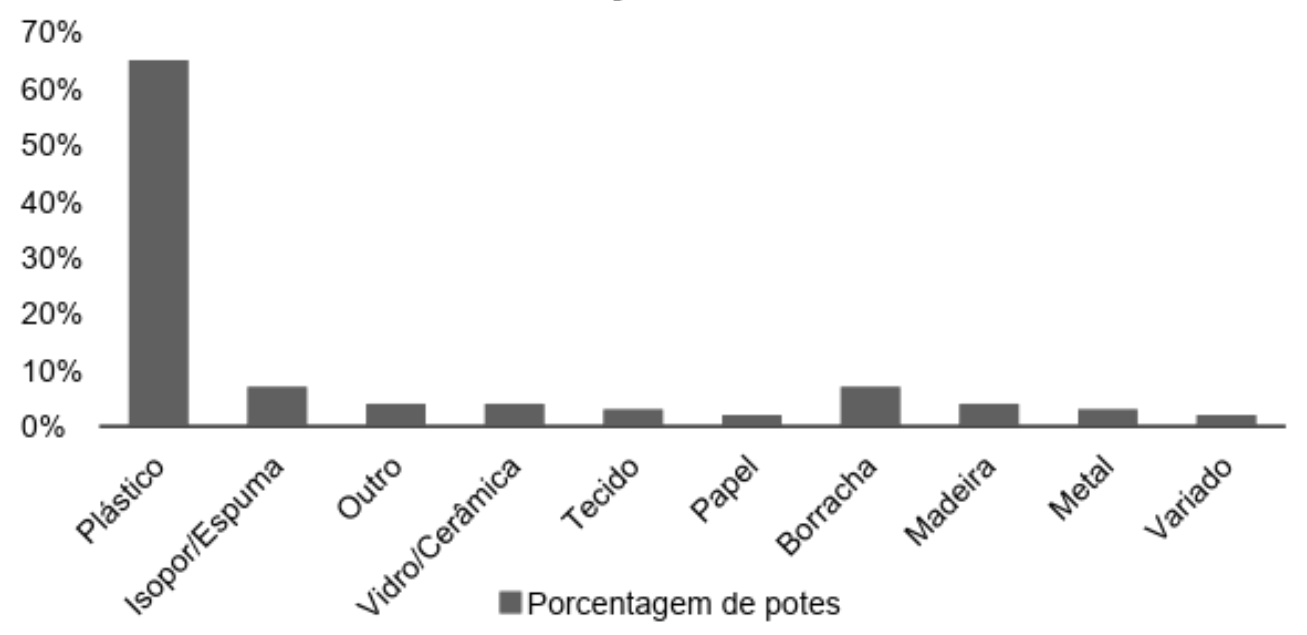

Figura 10: Quantidade em porcentagem do número de potes a partir da composição inserida.

Outro objetivo do projeto era confeccionar diferentes banners interativos, que foram usados em formato de imagem, confeccionados pelas voluntárias do projeto. Obteve-se como resultado 4 banners interativos, que foram usados no dia da exposição (Figura 11).

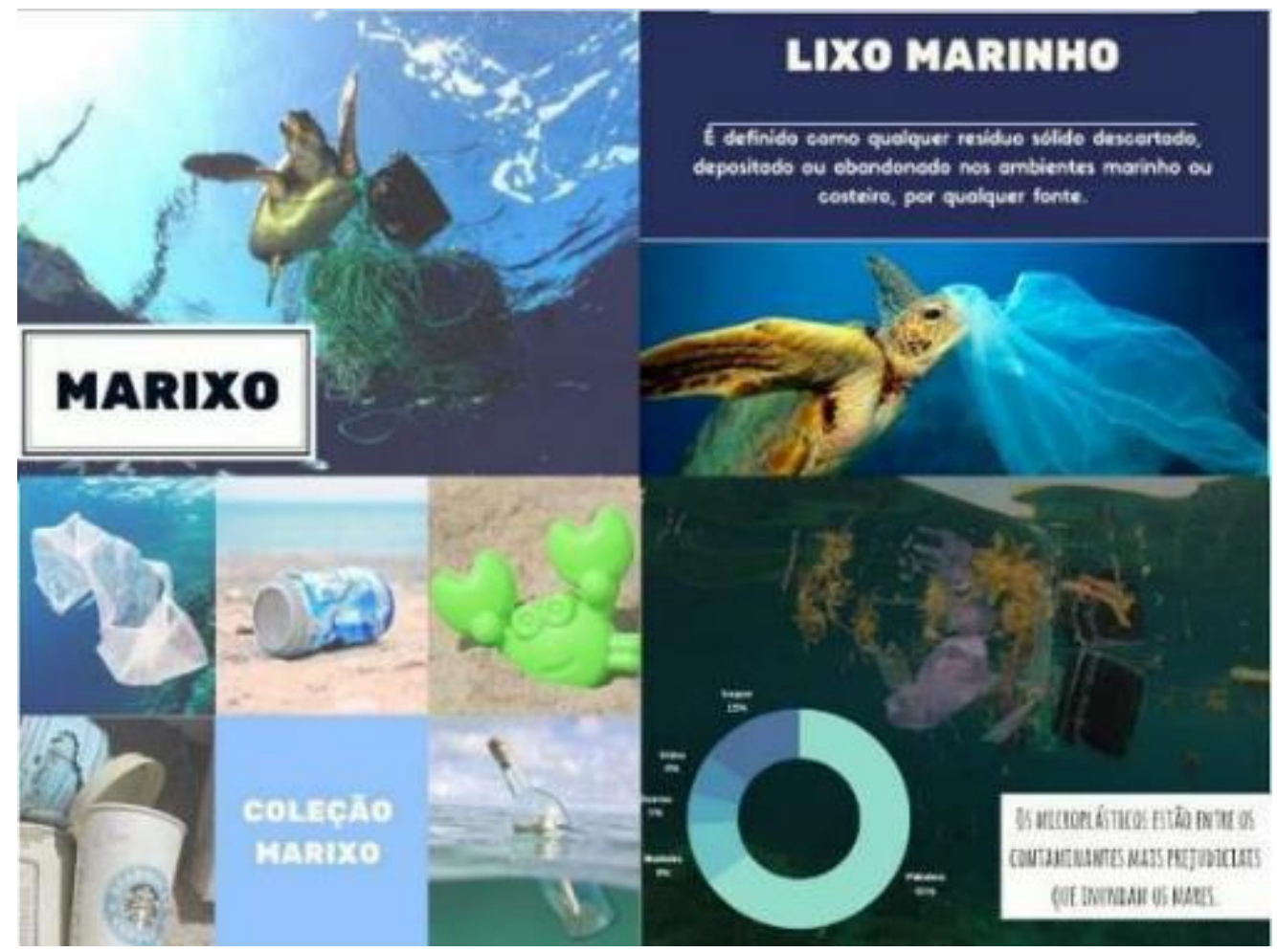

Figura 11: Banners confeccionados por voluntárias do projeto.

Fonte: adaptado de várias fontes disponíveis na internet.

Revbea, São Paulo, V. 14, № 4: 09-24, 2019. 
Quanto à análise dos questionários, pode-se tabular as respostas a todas as perguntas menos da pergunta 5, por ser opcional. A separação de respostas foi feita por duas categorias, por curso entre os alunos (Meio Ambiente, Mecânica e Informática), e os que não se identificaram por turma, ficaram na mesma categoria (Outros), com isso pode-se gerar quatro gráficos como resultado, um para cada pergunta.

Analisando a Figura 12, referente à pergunta 1, a maioria $(97 \%)$ acredita que a coleção estava apta para exercer tal função, obteve-se $3 \%$ de resultado referente ao "não sei", mas não houve justificativa para a resposta. Referente à pergunta 2 do questionário, onde se referia à avaliação se o tipo de abordagem poderia contribuir com uma maior sensibilização da sociedade perante o tema, houve a escolha unânime do sim (100\%), como mostra a Figura 13.

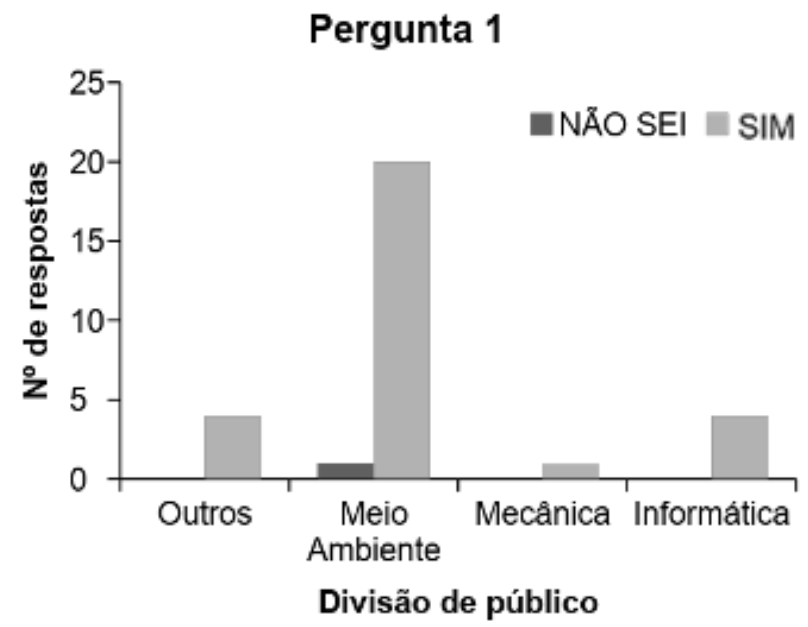

Figura 12: Respostas referentes à pergunta 1. Você acha que a coleção está apta para informar e/ou educar os cidadãos sobre a problemática do lixo marinho?

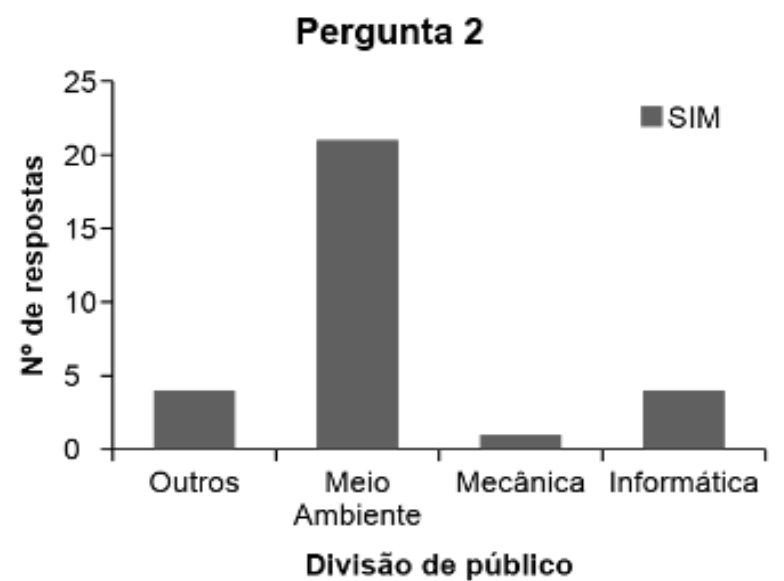

Figura 13: Respostas referentes à pergunta 2. Você acha que esse tipo de abordagem pode contribuir com uma maior sensibilização da sociedade perante o tema em questão? 
A pergunta 3 (Figura 14), algumas pessoas não souberam responder (10\%), mas foram justificados que somente o material não passava totalmente o objetivo do trabalho, necessitando de explicação complementar, assim como uma conversa interativa durante a exposição. Contudo em sua maioria as respostas foram $\operatorname{sim}(90 \%)$.

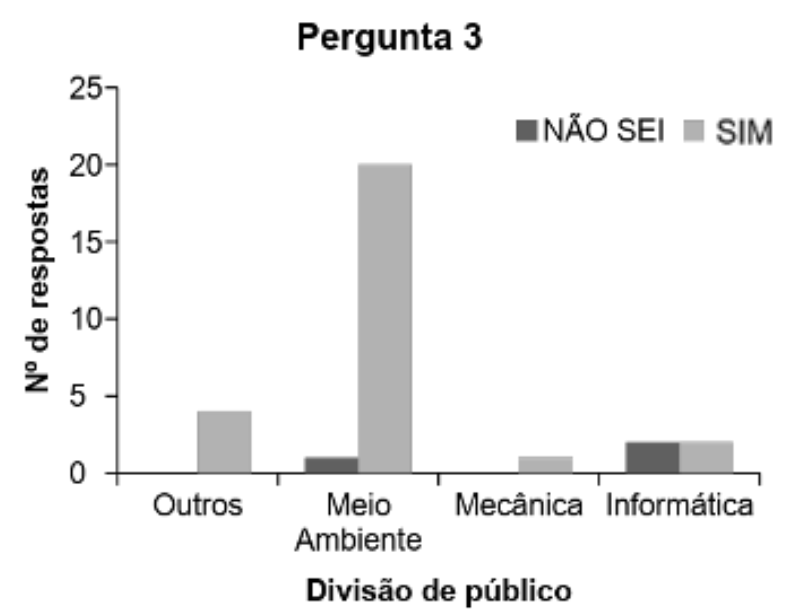

Figura 14: Respostas referentes à pergunta 3. Em sua opinião o material conseguiu transpor os conhecimentos técnicos sobre o tema de forma satisfatória neste tipo de abordagem?

A última questão analisada foi a que identificava o estado de espírito/emocional das pessoas após a exposição, basicamente perguntando com ela se sentiu. Algumas pessoas marcaram mais de um estado e ainda acrescentaram outros estados. Observou-se que a maioria se sentiu "revoltado" após saber de como o lixo marinho é abundante nas praias e como isso pode nos afetar, não somente aos humanos, mas também a outras espécies que necessitam do mesmo bioma ou biota para sua sobrevivência (Figura 15).

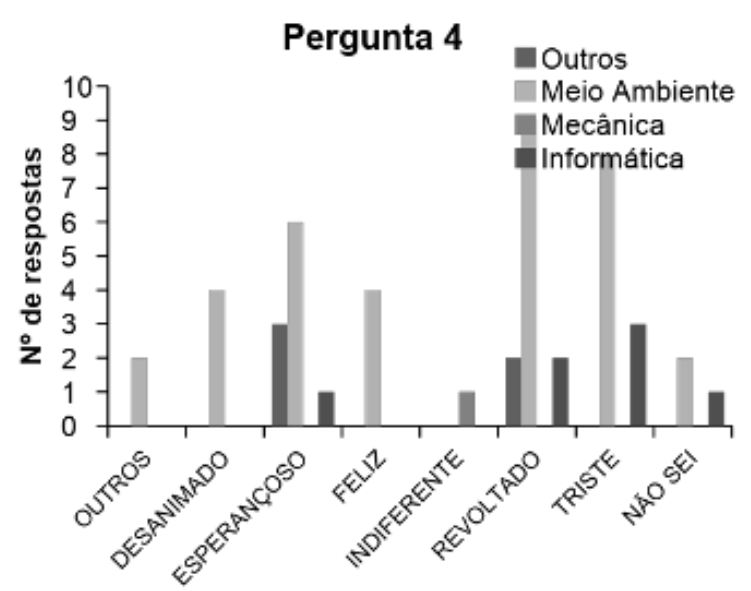

Figura 15: Respostas referente à pergunta 4. Defina como você se sentiu após a exposição. 
A última análise feita foi realizada com o chi-quadrado, visou responder a hipótese de que se o curso técnico cursado pelo visitante interfere na percepção. As perguntas utilizadas foram as 4 questões aplicadas no questionário. As perguntas 1, 2 e 4, não apresentaram diferenças significativas que pudessem demonstrar interferência. Já a pergunta 3, que se referia se a coleção teria sido capaz de passar conhecimentos técnicos de forma satisfatória, apresentou diferença entre os alunos do curso de meio ambiente e os demais cursos $\left(X^{2}=17.175\right.$, grau de liberdade $=2, p$-valor $\left.<0,001\right)$.

Quando analisadas as respostas, os alunos de meio ambiente responderam (absoluta e proporcionalmente) com maior frequência que "sim", ou seja, afirmando que a coleção consegue passar os conhecimentos técnicos sobre o tema de forma satisfatória. Estes alunos responderam de forma distinta dos alunos dos outros cursos (Mecânica e Informática), dos quais as respostas variaram entre "sim" e "não sei". Há a hipótese de que haja divergência pelo fato de que os alunos do curso de meio ambiente possuem em seu plano de curso uma disciplina voltada para os aspectos da Educação Ambiental. Com isso, desde o primeiro ano dentro da instituição os estudantes são incentivados a participar de projetos que visam o envolvimento com ferramentas de Educação Ambiental, inclusive podendo criar programas e iniciativas de promoção da EA. Por outro lado, os demais cursos não possuem esta disciplina em sua grade curricular e é pouco provável que tenham contato com o tema de forma direta, apenas indireta como a participação de exposições, seminários, entre outros.

\section{Considerações finais}

O que se pode concluir, resultante da pesquisa realizada, foi que a confecção de materiais científicos como "coleções" mostra-se como uma ferramenta fácil e prática no apoio a sensibilização e Educação Ambiental. A criação da coleção juntamente com a exposição trouxe, com base na percepção do público, que esta é uma ferramenta efetiva. Mas vale ressaltar que não basta utilizar este instrumento de ensino de maneira isolada. Para que o processo de sensibilização seja completo, é necessário o diálogo explicativo da coleção, não se limitando a uma linguagem técnica para abranger diferentes públicos e promovendo a Educação Ambiental sobre o tema. A coleção "Marixo" mostrouse uma iniciativa promotora à reflexão e acabou por envolver todos os participantes, que se propuseram a participar, posteriormente, em mais práticas relacionadas à temática de estudo. O material mostrou também ser de fácil acesso e transporte, pois a maioria dos participantes da exposição pegou os potes para que pudesse visualizar seus conteúdos. Assim, destaca-se a utilidade das coleções para aumentar o número de cidadãos envolvidos em pesquisas participativas.

Sugere-se que mais estudos sejam realizados sobre a efetiva sensibilização em longo prazo dos visitantes deste tipo de coleções, observandose a mudanças de hábitos que representem redução dos impactos dos resíduos sólidos sobre o ecossistema marinho. Além disso, a coleção pode ser utilizada para públicos de outras faixas etárias, sendo interessante avaliar a eficiência de sensibilização desses públicos também.

Revbea, São Paulo, V. 14, № 4: 09-24, 2019. 
Recomenda-se que mais coleções sejam desenvolvidas em território brasileiro, para aumentar o público abrangido. E por fim, pode-se ressaltar a importância do fortalecimento da Rede Brasileira de Coleções do Lixo em Ambiente Marinho (Re-Colixo), da qual a Marixo faz parte, como estratégia para a divulgação científica dessa problemática ambiental.

\section{Agradecimentos}

Agradecemos a todos que estiveram presentes ajudando e participando das atividades durante a elaboração do projeto, em especial à equipe composta por Edymari Gonzaga, Eduarda Lopes, Juliana Araújo e Mirelle Soares. Os autores também agradecem à Professora Dra. Rosana de Fátima Silveira Jammal Padilha pela revisão do manuscrito. Ainda vale agradecer à Rede Brasileira de Coleções Didáticas e Científicas do Lixo Marinho (Re-COLIXO), da qual a Marixo é participante, pela valorosa contribuição na divulgação das coleções didáticas e científicas em território nacional.

\section{Referências}

ARAÚJO, M. C. B.; COSTA, M. F. Lixo no ambiente marinho. Ciência Hoje, v. 32, n. 191, p. 64-67, 2003.

ARAÚJO, M.C.B.; COSTA, F.M. An analysis of the riverine contribution to the solid wastes contamination of an isolated beach at the Brazilian Northeast. Management of Environmental Quality: An International Journal. 2007a

BINSFELD, C.; ZANON, L. A Participação de Materiais de Divulgação Científica no Desenvolvimento de uma Situação de Estudo no Ensino Médio. Anais da Reunião Anual da Sociedade Brasileira de Química, 2007.

BRASIL. Lei de Diretrizes e Bases da Educação Nacional, Lei no 9394 de 20 de dezembro de 1996.

BORGES, A. Contribuições dos textos de divulgação científica para o ensino de Ciências na perspectiva dos professores. Acta Scientiae, v.14, n.1, 2012.

CHESHIRE, A.; ADLER, E.; BARBIÈRE, J.; COHEN, Y. UNEP/IOC Guidelines on survey and monitoring of marine litter. 2009.

COE, J.M.; ROGERS, D.B. Marine Debris: sources, impacts and solutions. Nova York: Springer Verlag, 431 p. 1997.

CORREA, D., FEJES, M. Levantamento e caracterização de materiais de divulgação como subsídio a divulgação científica de setores públicos e privados relacionados com projetos de educação socioambiental. Anais do II Seminário Hispano Brasileiro - CTS, p. 295-303, 2012

DURRELL, G.; DURRELL, L. O Naturalista Amador. Um guia prático ao mundo da natureza. Editora Martins Fontes. 314 pp, 1996.

IVAR DO SUL, J. A. Lixo marinho na área de desova de tartarugas marinhas do Litoral Norte da Bahia: consequências para o meio ambiente e moradores locais. 62p., Monografia de graduação, Fundação Universidade Federal do Rio Grande, Rio Grande do Sul, Brasil, 2005.

revista brasileira educação ambiental 
KRASILCHIK, M. Prática de Ensino de Biologia. 4. ${ }^{a}$ ed. rev e ampl., $2^{2}$ reimpr. - São Paulo: Editora da Universidade de São Paulo, 2008.

KRELLING, A.P.; WILLIAMS, A.T.; TURRA, A. Differences in perception and reaction of tourist groups to beach marine debris that can influence a loss of tourism revenue in coastal areas. Marine Policy, v. 85, p. 87-99, 2017.

MAEKAWA, E.; LAYRARGUES, P.P.; VAZZI, V. Educação Ambiental na escola: tá na lei, 2007. Disponível em: <https://lieas.fe.ufri.br/download/artigos/ ARTIGO-EDUCACAO ESCOLA TA NA LEI-.pdf> Acesso: 27/03/19.

MARANDINO, M.; RODRIGUES, J. Coleções como estratégia didática para a formação de professores na pedagogia e na licenciatura de ciências biológicas, 2014. Disponível em: <https://edisciplinas.usp.br/pluginfile.php/ 234549/mod resource/content/1/texto\%204\%20-\%20objetos\%20e\%20cole\% C3\%A7\%C3\%B5es.pdf> Acesso em: 27 mar. 2019.

MARANDINO, M.; SELLES, S.E.; FERREIRA, M.S. Ensino de Biologia: histórias e práticas em diferentes espaços educativos. São Paulo: Cortez, 2009. 215p.

PAPAVERO, N. Fundamentos práticos de taxonomia zoológica. São Paulo. 2ª edição. Editora UNESP. 1994.

PEREIRA, F. C. Microplásticos no ambiente marinho: mapeamento de fontes e identificação de mecanismos de gestão para minimização da perda de pellets plásticos. p. 133, 2014. Dissertação (Mestrado em Oceanografia Biológica) Biblioteca Digital, USP - São Paulo.

RODRIGUES, I., FRIEDRICH, A. Impactos do lixo marinho e Ação "Praia Local, Lixo Global". Disponível em: <http://ambientes.ambientebrasil.com.br/ agua/artigos agua salgada/impactos do lixo marinho e acao \%E2\%80\%9C praia local\%2C lixo global\%E2\%80\%9D.html>. Acesso em 27 mar. 2019.

TUDOR, D.T.; WILLIAMS, A.T. Development of a "Matrix Scoring Technique" to determine litter sources at a Bristol Channel beach. Journal of Coastal Conservation, v. 10, n. 1, p. 119-127, 2004.

VALENTE, M. E. A Educação em Museu: o público de hoje no museu de ontem. Dissertação (Mestrado em Educação) - Departamento de Educação, PUC - Rio, Rio de Janeiro, 1995.

VERDI, L. Sarney Filho reafirma combate ao lixo no mar. Ministro reforça importância de ações para conter a contaminação dos oceanos e defende a criação do Santuário das Baleias do Atlântico Sul. Disponível em: <http://www. mma.gov.br/index.php/comunicacao/agencia-informma?view=blog\&id=2463>.

Acesso em: 13 dez. 2017.

WHITMIRE, S.L.; VAN BLOEM, S.J.; TOLINE, C.A. Quantification of Microplastics on National Park Beaches. Disponível em: $<$ http://npshistory.com/publications/water/microplastics.pdf $>$. Acesso em: 13 dez. 2017. 